\title{
B-Mode Ultrasound Imaging
}

National Cancer Institute

\section{Source}

National Cancer Institute. B-Mode Ultrasound Imaging. NCI Thesaurus. Code C162558.

A two-dimensional ultrasound imaging that displays the acoustic impedance of crosssection of tissue as bright dots representing the ultrasound echoes. The brightness of each dot is determined by the amplitude of the returned echo signal. This is the most common mode of ultrasound imaging. 